\title{
Inspired Leadership for Turbulent Times \& the Power of Youth
}

\author{
Neelesh Gupta, Rajesh Gurumoorthy \& Ajnav Deka \\ Human Resources - The Tata Power Company Limited
}

\begin{abstract}
Clouds of turbulence are in the air my friend and strafing through these times has been a bumpy ride for almost everybody. Many organizations have seen their dusk, some have seen the dawn too and it has been barely a few who have been able to shine bright. These turbulent times have been classified under economic slowdown, unemployment as well as workforce unavailability, social uprising, war for resources etc. and all these factors, individually or in conjunction have led to huge ambiguities for businesses. Many types of leaders have tasted these waters and some of them, who have been able to manage these, have soared. One common attribute that has been common among all the dons (read dawns) in these times has been their ability to induce action in others and steer the team to glory. Such inspired leaders and their leadership hold the key to the good times that lie ahead of this turbulence. This paper presents a model on how the leadership of an inspired leader can rally the masses generally and the youth specifically, to steer out of these turbulent times and build a better \& a more sustainable tomorrow.

This paper is the outcome of primary as well as secondary research. The results of the primary research are detailed in Annexure I and the sources of the secondary research are detailed in Annexure II.
\end{abstract}

\section{Introduction}

It's been a decade since global markets are witnessing the clouds of turbulence and many less organizations have been successfully able to strife through these towards growth and prosperity. The ray of hope in these times has been attributed to varied forms of leadership and the persona of the leaders who have held fort. In this paper, we present a model which we feel could steer organizations through the times of turbulence. Let us go ahead by first defining a few terms:-

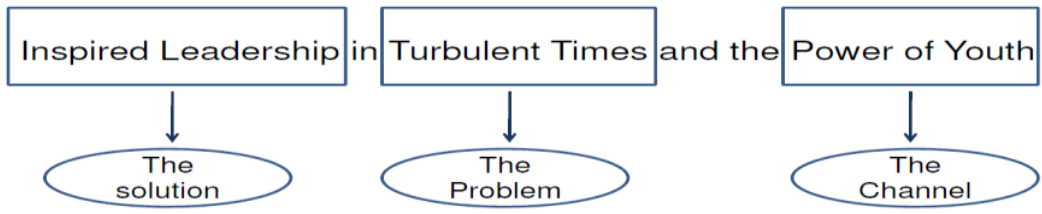

Fig - 1: The dissection of the statement

1. Inspired Leadership:- "Great leaders are able to inspire people to act. Those who are able to inspire give people a sense of purpose or belonging that has little to do with external incentive or benefit to be gained. Those who truly lead are able to create a following of people who act not because they were swayed but because they were inspired. For those who are inspired, the motivation to act is deeply personal. Those who are able to inspire will create a following of people-supporters, voters, customers, workers-who act for the good of the whole not because they have to, but because they want to."

- Simon Serek

Some qualities that a leader must definitely possess are enumerated in the grid below:

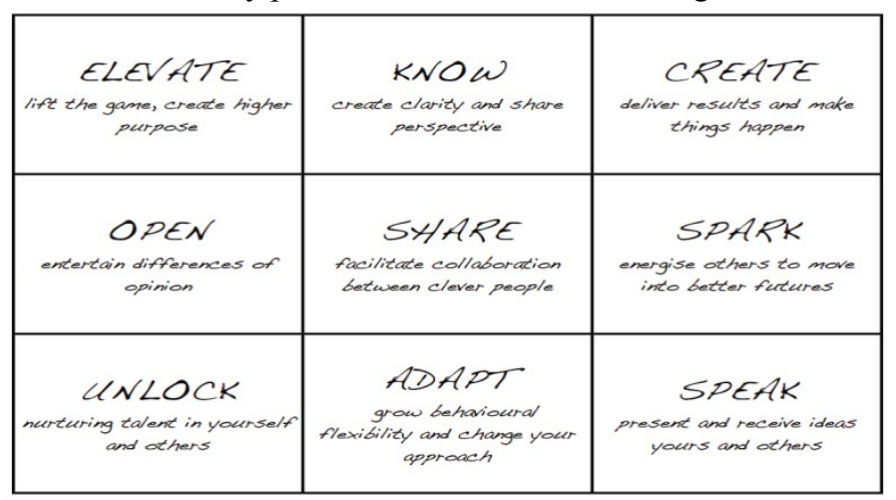

Fig 2: Desired qualities of an inspirational leader 
2. Turbulent Times:- A period caused by an event(s), having the potential to derail positive momentum or create instability can broadly be classified as turbulence.

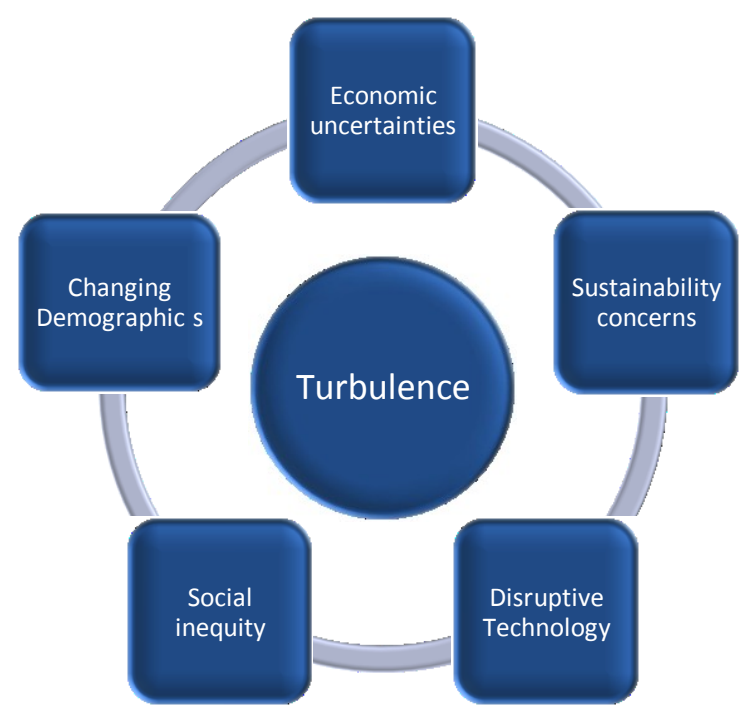

Fig 3: The turbulence circle

3. The Power of Youth:- The United Nations defines youth as people between ages 15 and 24. By this measure, there are approximately 240 million youth in India, about $20 \%$ of the population, according to preliminary projections from the 2011 census. That's up from 195 million in 2001. Also, the median age in India is 25 . This essentially means that the leaders of this country find themselves at cross roads. This youth power can either be harnessed for fast-tracking the economy or it can turn out to be the biggest liability in our growth story.

Some of the key factors which give rise to Youth Power, which need to be leveraged by Leaders of today, are as under:

- Quantum - Increasing numbers in favour of youth

- Passion

- Innovative thinking

- Ability to question status quo

- Uber connectivity

- Adaptability

- Resilience

\section{Approach}

A great scientist once said, "Leading by example is not the main means of influencing people, it is the only means" and he was no other than Albert Einstein. Think about a scenario wherein we could set up an example (read legacy) of leading people (read youth) by means of inner inspiration. If such legacies could be archetyped, the turbulence in the external environment could be minimized.

To realize such a concept we need to find answers to a few questions:-

\section{What is causing this turbulence today?}

The factors which we feel cause turbulence in our operating environment, have been classified into five broad categories. These are detailed below:

I. Demographic profile of the population / workforce: The demographic profile of the productive workforce is changing significantly in different countries, posing varied challenges to the leaders in these countries. In some countries like Japan, a rapidly aging population combined with low birth rates has resulted in a big challenge to the state in dealing with the dependence of the aged population. On the other hand, for countries like India, there is an opportunity to reap the demographic dividend in terms of a large, young population and huge numbers of youth getting added to the potential workforce each year. It is incumbent upon the state and the Corporate sector to provide reasonable livelihood opportunities to this burgeoning talent pool. It is however observed that job creation is not keeping pace with the growth in the workforce year on year. Moreover, the lack of skills for application in real world jobs is a big concern. The global youth unemployment rate, estimated at 
12.6 per cent in 2013, is close to its crisis peak. 73 million young people are estimated to be unemployed in 2013.1 At the same time, informal employment among young people remains pervasive and transitions to decent work are slow and difficult. (Source: ILO Report, 2013)

In conjunction, handling the ambitious aspirations of a large young workforce is also a massive challenge for all leaders.

II. Economic uncertainties: The world economy today is undergoing upheaval. The global rate of economic growth has slowed down, most notably after the sub-prime crisis and European economic crisis. This in turn has had a cascading effect on all national economies with more and more funds being utilized to revive creaking economies. Even BRIC countries which were at the vanguard of driving global economic growth, are faced with a slowdown in their ambitions. In India specifically, in addition to the bleak global outlook, the economy is struggling on account of various factors like lack of effective governance, policy paralysis, excessive dependence on imports over exports and fractious political system, among others. This is borne out by the below illustrations on GDP, Fiscal and Current Account Deficit measures, as per a Deloitte Report.

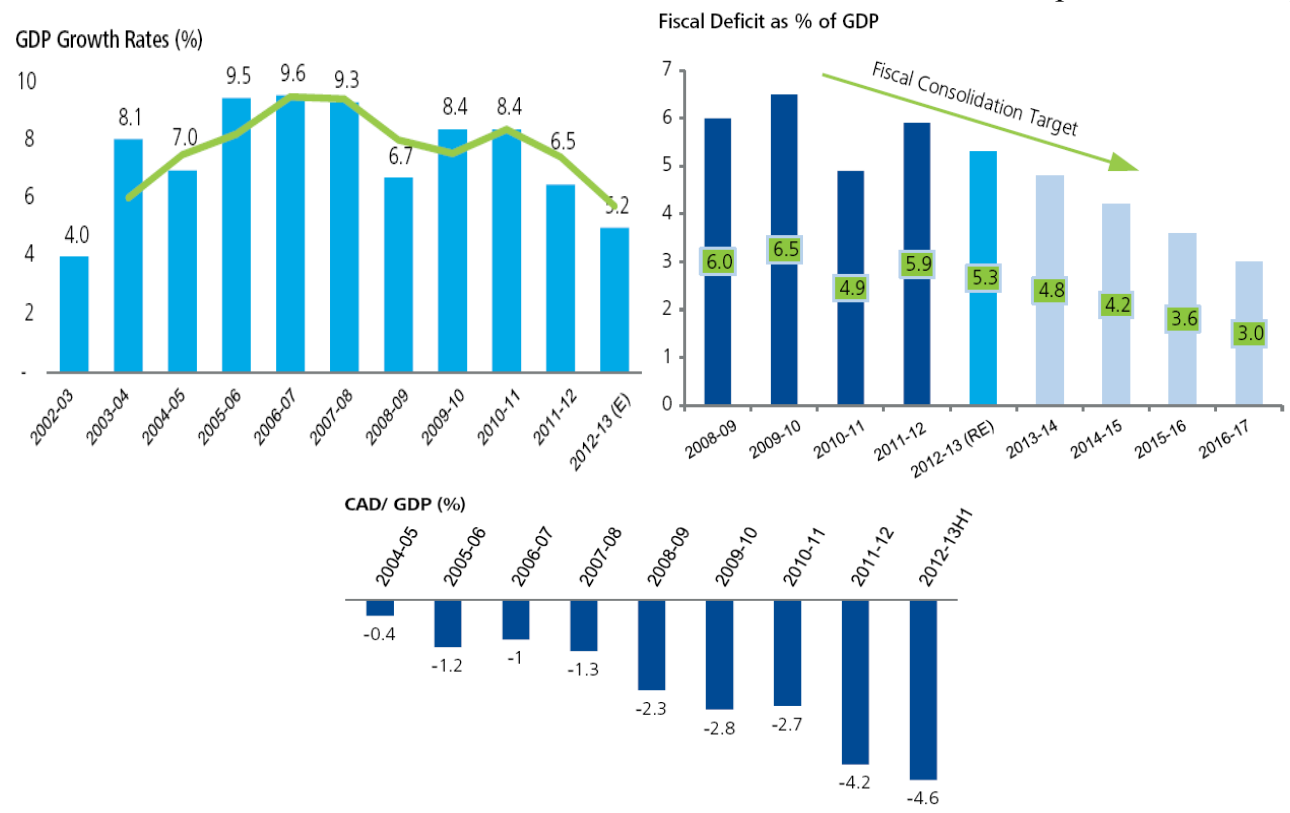

III. Disruptive Technologies: This is age of technological advancements and disruptive technological innovations are the order of the day. In many areas, technological changes are rendering most running technologies obsolete and thereby reducing their useful life. These disruptions place a premium on cutting edge research, something that may not be within the reach of all involved. In this case, it is the innovators who will be able to stay ahead of the curve. A good example of this is Google which has managed to build a global reputation on the strength of its robust innovation pipeline.

IV. Social inequity: In any growth story, it is imperative that all sections of society be an equal stakeholder and that the benefit of development percolate down to the lowest levels of society. However, whenever this is not so, it leads to unrest and a sense of disenchantment. This is quite evident in a country like India where there is a clear divide between the 'haves' and the 'have-nots'. Also, the fruit of economic development tends to be skewed towards the urban, educated populace. This not only leads to large scale migration of manpower seeking opportunities and thereby burdening already creaking urban infrastructure, it also leads to violent assertions of so-called rights to a share of the pie. An atmosphere of unrest is most inimical to the Corporate sector as it will restrict value creation opportunities as well as to society at large.

V. Concerns over Sustainability: There is a real concern today that our natural resources, which have satiated our developmental needs for ages, are increasingly becoming strained due to the increased exploitation. Also, the by-product of development has been a strain on nature, with increasing pollution and climate change implications. As many researchers have pointed out, climate change is already beginning to have catastrophic effects on human life worldwide, with extreme weather events becoming the new norm. The failure of global powers to reach a consensus and mutual appreciation of their socio-economical imperatives is a further cause for concern as the world increasing stares multiple doomsday scenarios. Sustainability has undeniably become one of the key cornerstones of global policy making by leaders. Eg. The push towards committing all nations towards reduction of Carbon emissions in the followup to the Kyoto protocol. 


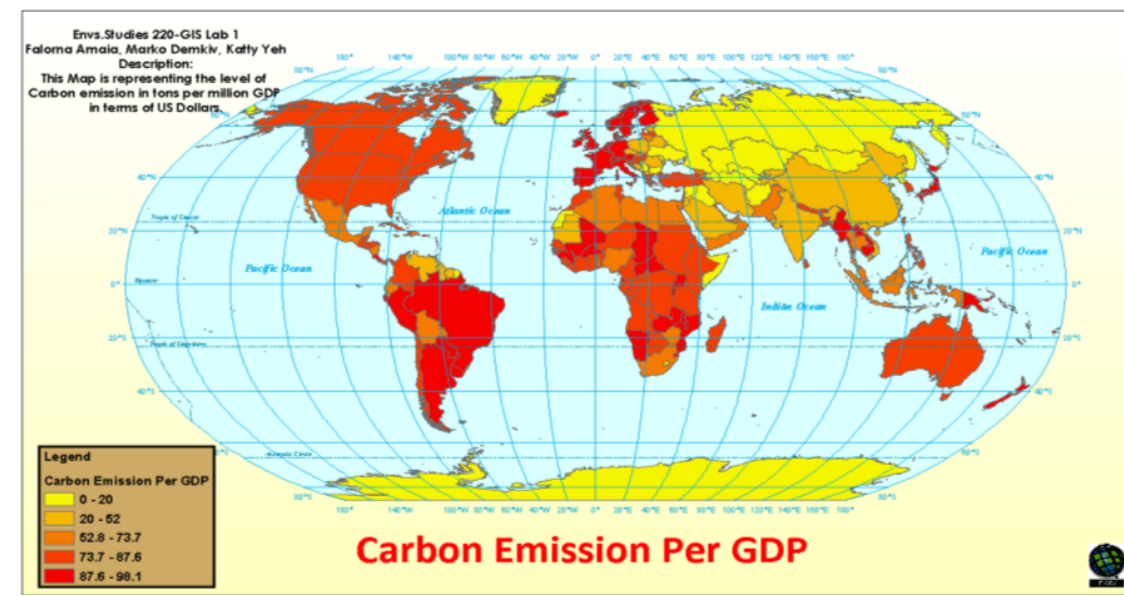

Source: Lewis \& Clarke College Research

\section{What kind of new behaviors must leaders display in times of today to build sustainable organizations of consequence?}

As John Kotter notes in his 1996 book Leading Change, leadership is a critical driver of an organization's ability to cope and adapt to change. Therefore, leaders first need to be the change that they want to see. As new generations begin to make their mark in the workplace, the notion of what a leader is, and needs to be, is being challenged. Transformed business models, faster information flows, stiffer competition, and changing worker and customer demographics mean leadership styles need to change, to be more collaborative. Keeping pace with evolving economic, social, and technical norms will require additional competencies, an understanding of a diverse and fragmented world and a keen sense of self-awareness and humility.

We thus propose the following model for inspired leadership, with a real world analogy:

\section{The Model}

Figure 5 here represents what are the four broad principles of inspired leadership that a leader should demonstrate and then should ensure that they become infused into the culture of the organization. These principles are further defined into tangible behaviours which leaders must exhibit:

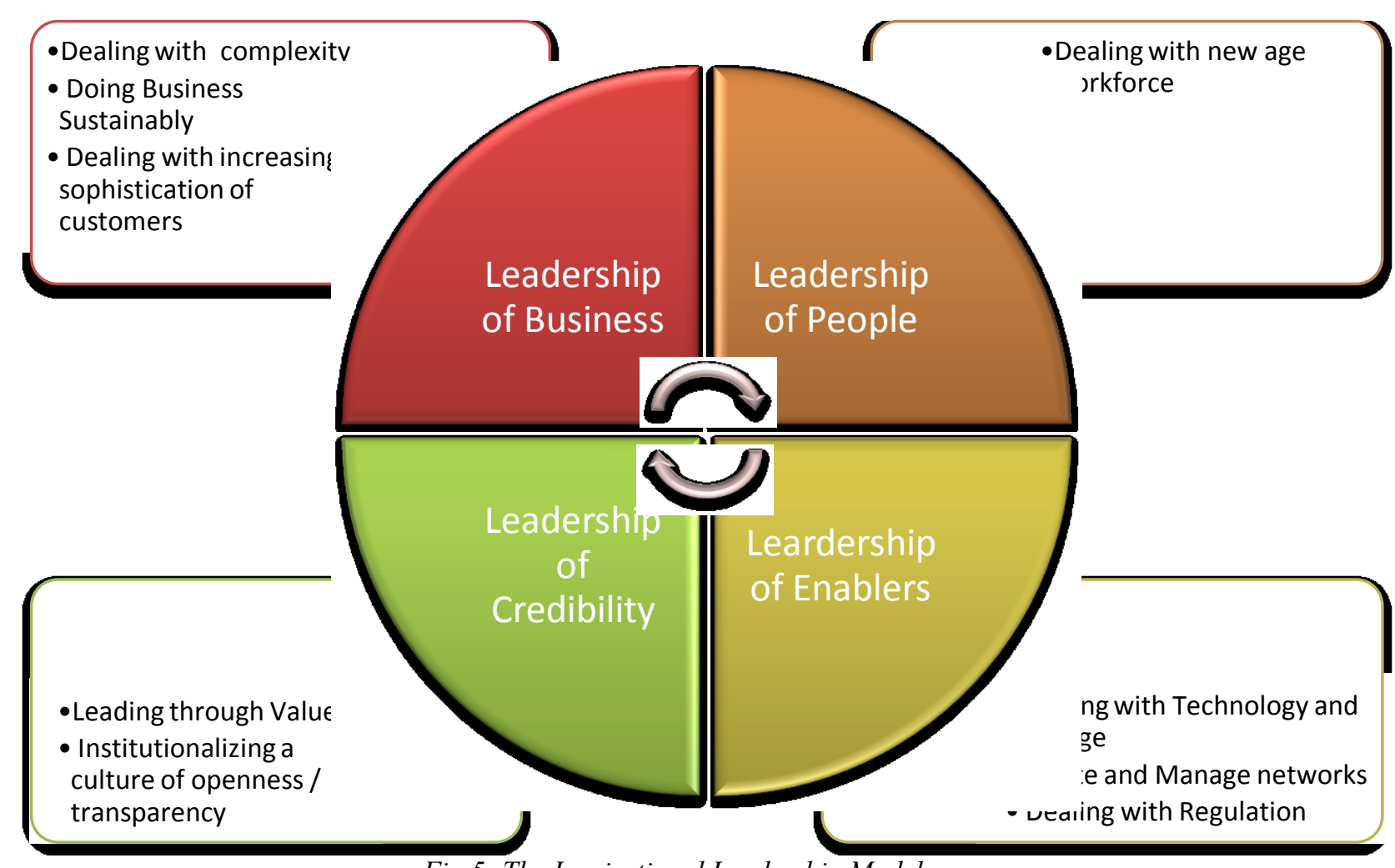

Fig 5: The Inspirational Leadership Model 
The model of how inspirational leadership may apply in the real world is explained below through an analogy. Also, each of the behaviours indicated in the model is explained in detail.

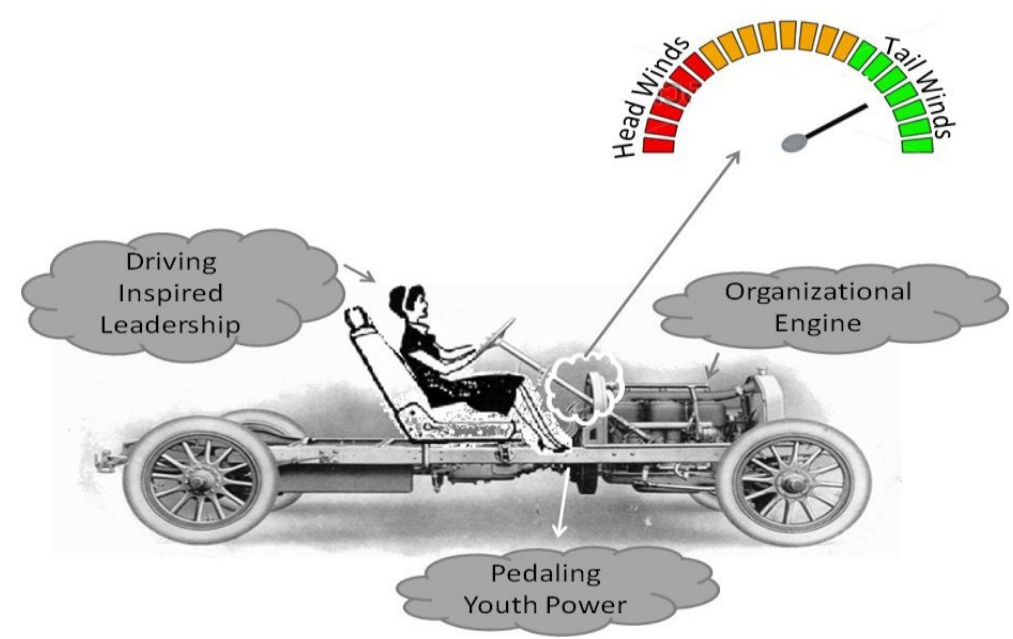

Fig 6: Our analogy to illustrate the workings of Inspired Leadership

The components of this illustration are:-

- The driver -the inspirational leader

- The pedal - symbolic of the power of youth, having the potential to accelerate the organizations growth rate

- The engine - is the organization as a whole

- Dashboard - The sense of direction that the leader has w.r.t. external environment

Figure 6 represents a leadership channelization mechanism, which is an organization driven by inspired leadership. Till the time youth power is pedaled by inspired leadership, the organizational engine shall continue to roar towards prosperity. The point to note is the concept of tail winds and head winds. Tail winds here denote a favorable period from an organization's perspective and head winds denote a similarly turbulent period.

Some of the specific behaviours that leaders must display in times of today are as under:

I. Dealing with Complexity: Complexity exists not only in the operating environment but also in terms of the speed of decision making required in a sea of rapid information flows. Resolving ambiguities by faster processing of information and tackling constantly moving targets will be critical. Leaders would thus need to be more agile and also delegate authority down the line, in order to continue looking at the big picture.

II. Dealing with Technology and Change: With constant technological advancements driving change, it is essential for leaders to ensure that a culture of innovation is embedded throughout the organization. Innovation is not necessarily in terms of products but could also be of processes, and indeed incremental.

III. Dealing with changing expectations of workforce: With the workforce not only getting younger but also more diverse in terms of thought processes, skill levels and cultural touches, it is essential for leaders to understand and thereby manage different drivers of performance. The workforce is increasingly looking towards obtaining 'meaningful' work instead of merely a paycheck. Also, the hierarchies of the past are increasingly breaking down and leaders need to engage with the workforce, not through authority, but by inspiring through vision and clarity of purpose. The leadership style will increasingly need to be participative and collaborative. Leaders would also need to actively promote diversity as a means to achieving better thought processes and results.

IV. Institutionalizing a culture of openness / transparency: Communication skills of leaders are increasingly being tested as open, two-way communication is essential for building and maintaining trust. This includes communication with not only internal stakeholders, but also external ones like suppliers, shareholders, communities etc.

V. Doing Business Sustainably: This does not merely imply longevity of the business. It means conducting business in a manner which supports the ideal of Sustainability by taking care of ecological and social accountabilities and thereby Corporate reputation. This also gives the message that financial bottom line is not the 'be-all and end-all'.

VI. Dealing with increasing sophistication of customers: As competition grows along with commoditization of products and services, the value proposition presented to the customer will be more critical than ever. The customer base will increasingly get fragmented, each posing unique challenges, which leaders will be expected to differentiate and satisfy. In other words, leaders will need to display an ability to sense evolving customer needs, which may not be explicitly expressed today but is expected to surface on the horizon. 
VII. Dealing with Regulation: Beyond government regulation, there will be more oversight and more scrutiny by non-governmental organizations and other stakeholders. Leaders will have to deal more with the levers of governance and become more comfortable with oversight from outside, including specific country regulations. The costs of non-compliance, especially for corporate and personal reputation, will be high. This would need to be supported by vocal advocacy be leaders for the cause that they believe in.

VIII. Create and Manage networks: The world of today and tomorrow depends heavily on the networks and relationships that are established between key stakeholders. In order to be effective, leaders need to have an evolved ability to not only establish but to sustain and manage key networks. This is especially critical looking at the explosion of social networking and the powerful connections that can be established today. Through active understanding and management of the power of networks, leaders can transcend numerous boundaries.

IX. Leading through Values: Linked to increasing complexity of the operating environment and all the factors mentioned above, is an inherent truism that there are going to be numerous ethical questions that will crop up regularly for which a leader has to deep dive within himself / herself in order to find an effective resolution. This can only be possible if the leader establishes and promotes a strong value based judgement framework such that the entire organization appreciates as well internalizes the same.

As Theodore Roosevelt Malloch, who is the Research Professor for the Spiritual Capital Initiative at Yale University, and chairman \& CEO, The Global Governance Fiduciary, says, the obsession with posting great results, quarter after quarter has resulted in a culture that puts emphasis on, and rewards, certain kinds of behaviour, making it harder for companies and individuals to resist it. It's important to give people training on ethics, bring about ethical awareness and use that as a larger framework to shift corporate culture. Companies have to dedicate themselves to being more ethical and change organisational behaviour to this end-and this has to start at the top.

We feel that by harnessing the power of youth and the internalization of new age leadership competencies by drivers of change, an organization can reap benefits of engagement, innovation, efficiency, productivity and agility.

\section{What should leaders do to channelize the young energy for organizational value creation as well as societal good?}

Prior to understanding what leaders need to do to channelize the young energy, it may be useful to understand some of the key attributes of youth that require the specific attention of senior leaders. These are listed below:

I. Need for autonomy (dislike of micro management)

II. Developmental Feedback (and lots of it!)

III. Immediate Recognition

IV. Challenging responsibilities (demand trust)

V. Differential Rewards (Greater rewards for meritorious performance)

VI. A healthy balance between professional and personal lives

VII. A refusal to accept status quo (Need to bring about positive change)

VIII. Need for a role model (to look up to)

Some of the levers to channelize these bubbling energies have been listed in the table:

\begin{tabular}{|l|l|}
\hline \multicolumn{1}{|c|}{$\begin{array}{c}\text { Attributes of } \\
\text { Youth }\end{array}$} \\
autonomy \\
Developmental \\
Feedback
\end{tabular}

Fig 7-Levers to channelize youth leadership 


\section{Case Study:}

Tata Power has evolved from being a traditional power utility primarily being a single city/ single state Company to a dynamic one that now has a national and international footprint, with a strategic intent of achieving 26,000 MW Power Generation by 2020. It is the only Indian company with a significant international presence (in this sector) with an installed capacity of $8521 \mathrm{MW}$ energy generation. However, an alarming fact that faces Tata power today is that with the current demographics, almost $50 \%$ of the Senior Leadership will retire by 2016 and $70 \%$ by 2020 . Therefore grooming leaders down the line is critical for the Company. Additionally, Manpower planning will have to evolve in terms of a ramp up, to support the growth \& diversification and emerging structure in the light of our vision for 2020. As a mitigation strategy, it has been consciously changing the lateral to campus mix from 61:39 in FY10 to 42:58 in FY12 and now further enhanced the youth factor by creating a 30:70 mix. With such a tall task at hand and recognizing the contribution of youth in its transformation in the last 5 years, to reach its current position of strength, the Company continues to further and enhance its Talent Management and Leadership Development initiatives, with a clear focus on grooming the leaders of the future. Some of the key leadership development initiatives of the Company are elucidated below:

\begin{tabular}{|c|c|}
\hline Accelerated Career Enhanoement & $\begin{array}{l}\text { Accelerated Career Enhancement } \\
\text { (ACE): Fast track career programme for } \\
\text { young executives at Tata Power. ACE is } \\
\text { an industry recognised best practice. After } \\
\text { a rigorous selection process, the selected } \\
\text { candidates go through a training program } \\
\text { at IIM-Ahmedabad. They are then exposed } \\
\text { to challenging assignments, mentoring and } \\
\text { fast track growth. }\end{array}$ \\
\hline Shikhar & $\begin{array}{l}\text { Shikhar Awards:- Annual business plan } \\
\text { competition for young executives at Tata } \\
\text { Power based on a single theme decided } \\
\text { for the year. The current year's theme was } \\
\text { innovation, wherein } 40 \text { young employees } \\
\text { participated. }\end{array}$ \\
\hline 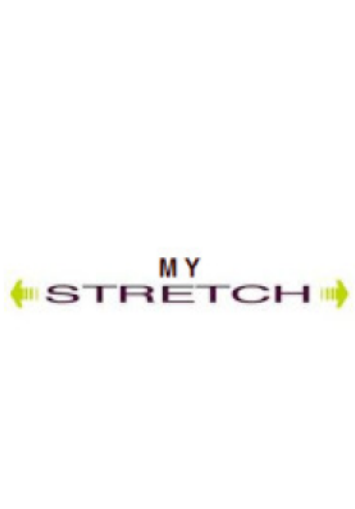 & $\begin{array}{l}\text { My Stretch: Platform for young executives } \\
\text { to work on active assignments through } \\
\text { their voluntary personal stretch, viz., } \\
\text { stretch beyond their set KRAs thereby } \\
\text { utilising their high energy levels } \\
\text { constructively towards organizational } \\
\text { ends. }\end{array}$ \\
\hline
\end{tabular}




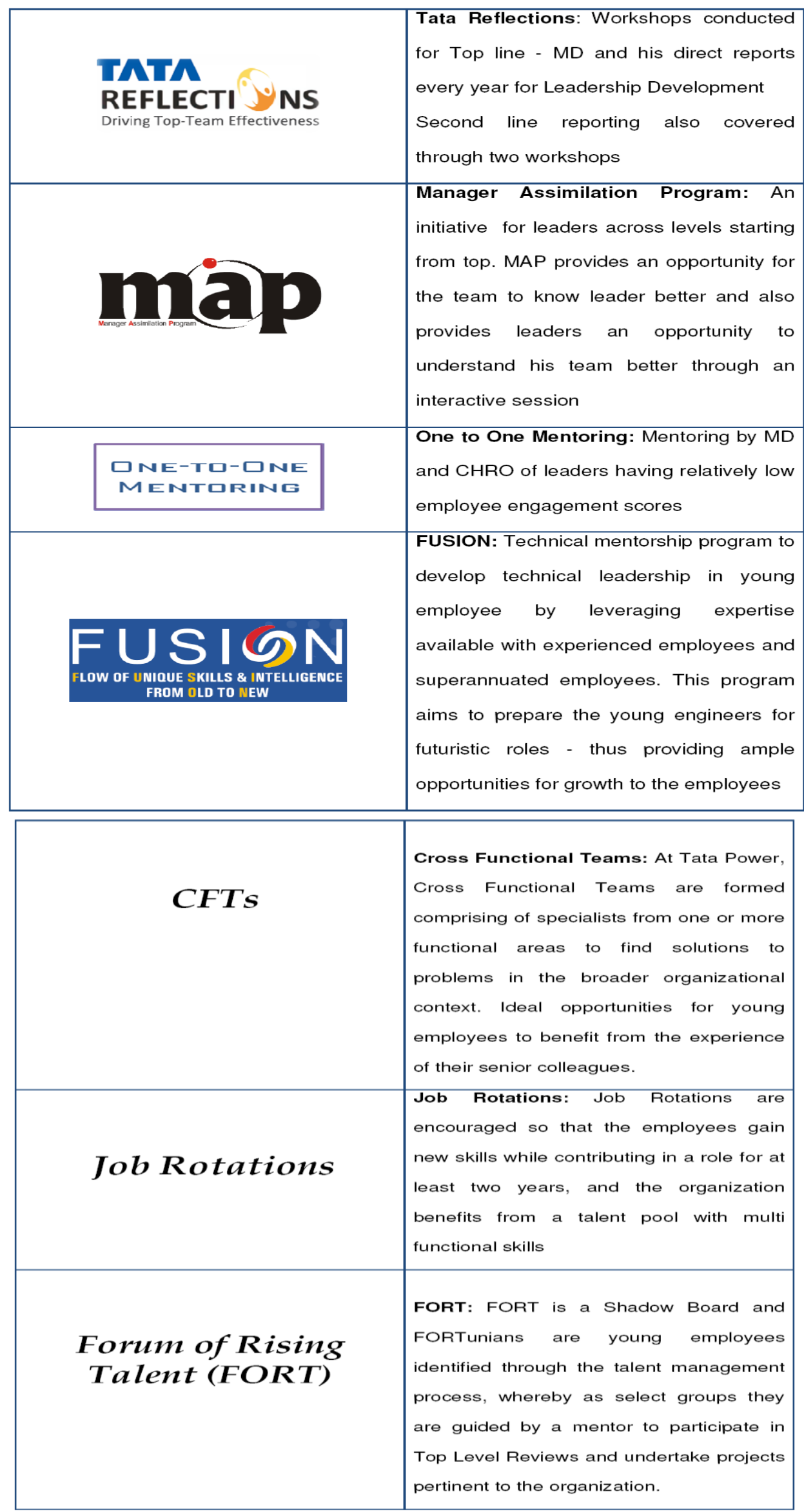




\begin{tabular}{|l|l|}
\hline Talent Management & \begin{tabular}{l} 
Talent Management : Maintaining a talent \\
pool of $4.5 \%$ with a big focus on young \\
managers, after a rigoruous process of \\
identifying top talent and finalizing \\
individual development plans like \\
mentoring, shadowing, job rotation, \\
training, etc. Thes IDPs are tracked on \\
monthly basis. \\
\hline Succession Planning: Ensuring that for \\
each critical position in the Company, \\
there are successors identified in "Drop \\
Dead"/ Immediate, 1-2 years and 3-5 \\
years categories. Subsequently ten \\
development mechanisms are applied to \\
create Individual Development Plans and \\
track them on monthly basis.
\end{tabular} \\
\hline Planing
\end{tabular}

\section{Conclusion:}

In summary, it cannot be denied that tough times are here to stay and that there is no country which is today not affected by this in some way or the other. However, we feel that there is sufficient cause for optimism in the belief that firm and inspired leadership will surely ease the transition process towards a better tomorrow. Specifically, in a developing economy in India, the opportunities are as tremendous as the challenges it faces. The demographic dividend as discussed in the paper earlier is one of the biggest opportunities that the leaders today need to capitalize on in order to propel the development agenda and indeed, steal a march on even developed countries which today face an increasingly ageing workforce and economic slowdown. However, if not turned to an advantage, the same dividend could very easily turn into one of the biggest liabilities. The stage is all set for the new-age leaders to show their true mettle!

\section{ANNEXURE I \\ PRIMARY RESEARCH CONDUCTED THROUGH SENIOR LEADERS IN TATA POWER:}

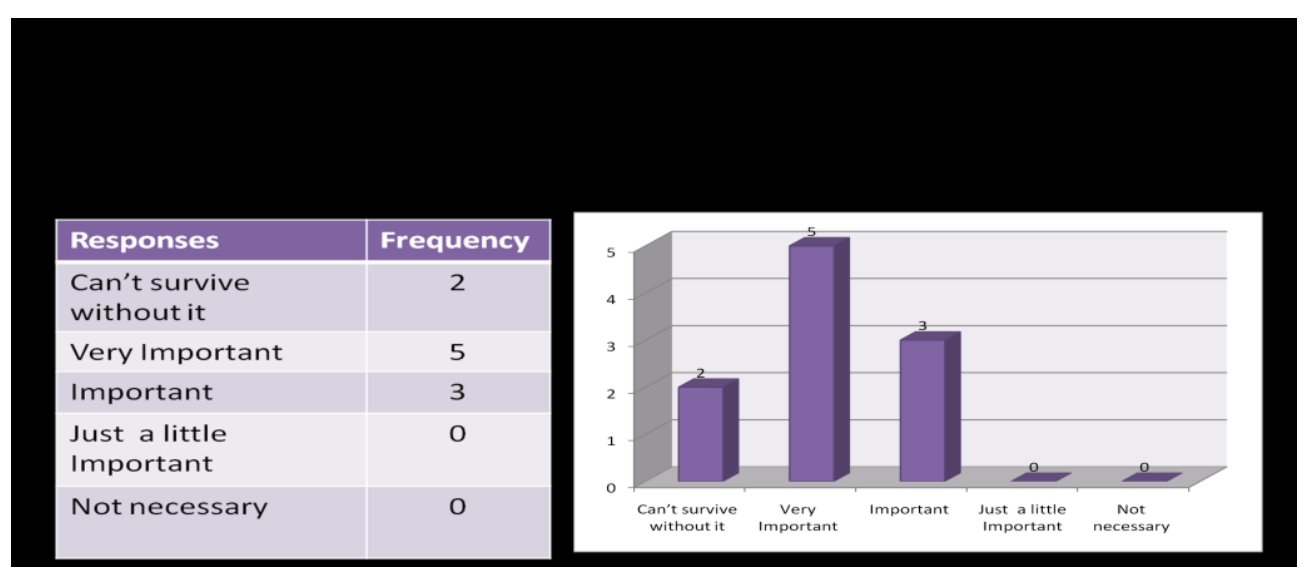

Analysis: Respondents do give credence to the importance of leadership in dealing with turbulent times 


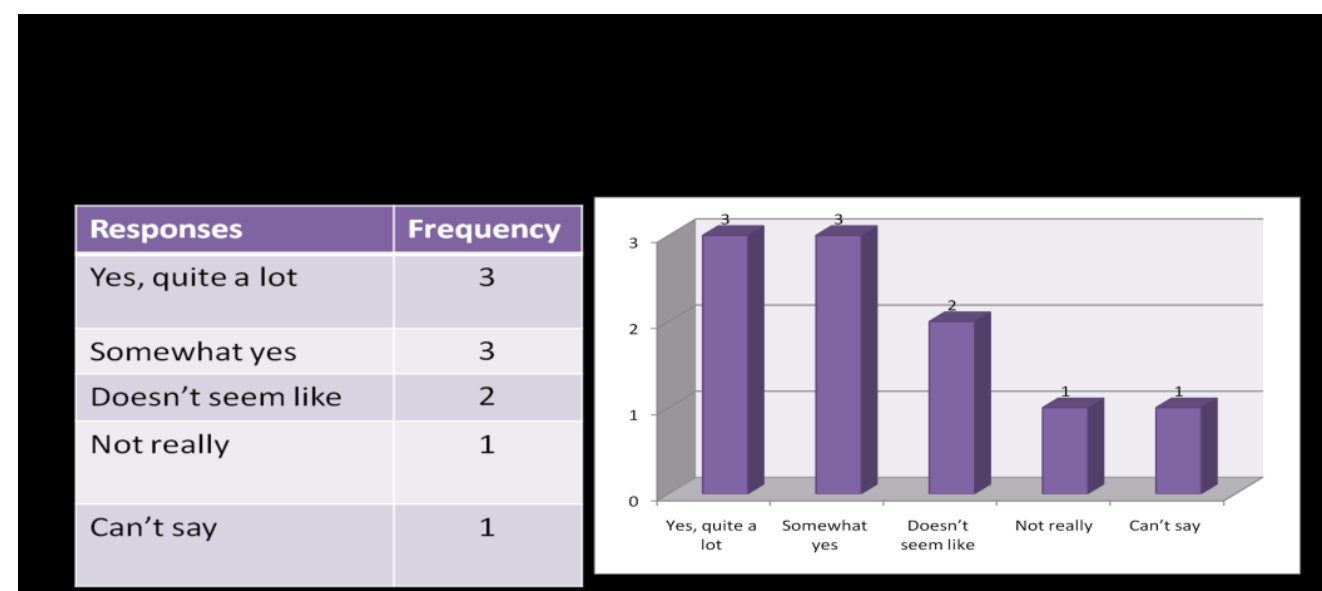

Analysis: Respondents acknowledged the fact that managing people is going to require whole new competencies on part of the leaders

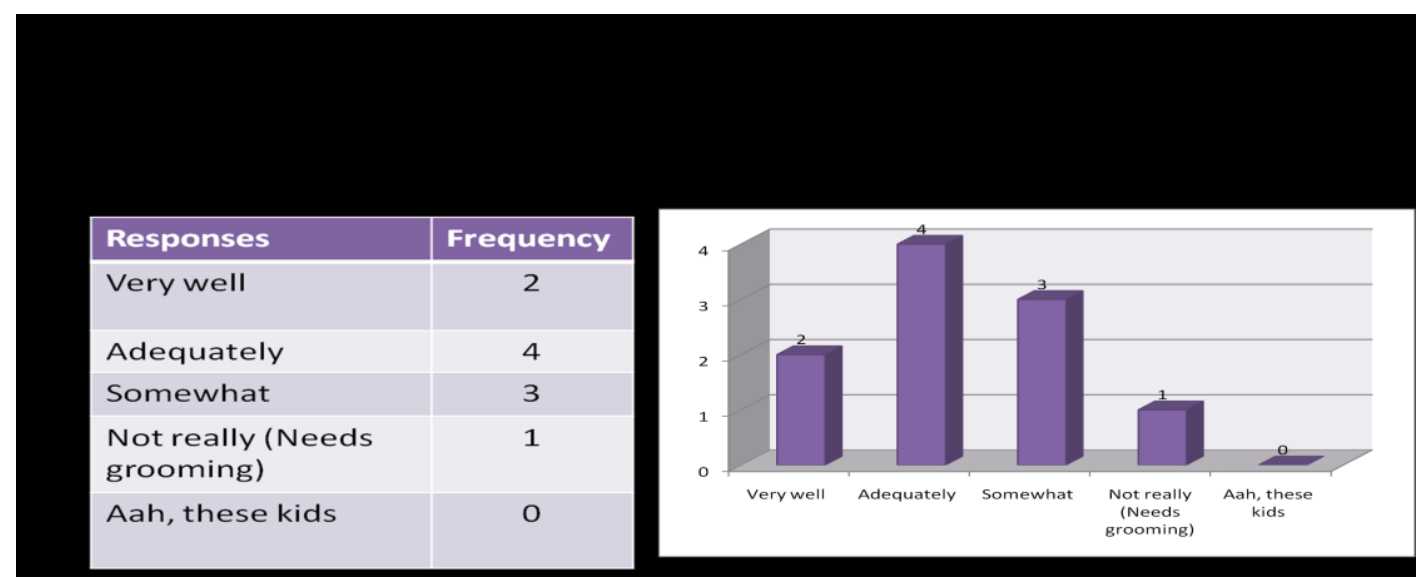

Analysis: Respondents indicated that they do not think youth are fully prepared to take on all challenges and that seniors still have a role to play in guiding them

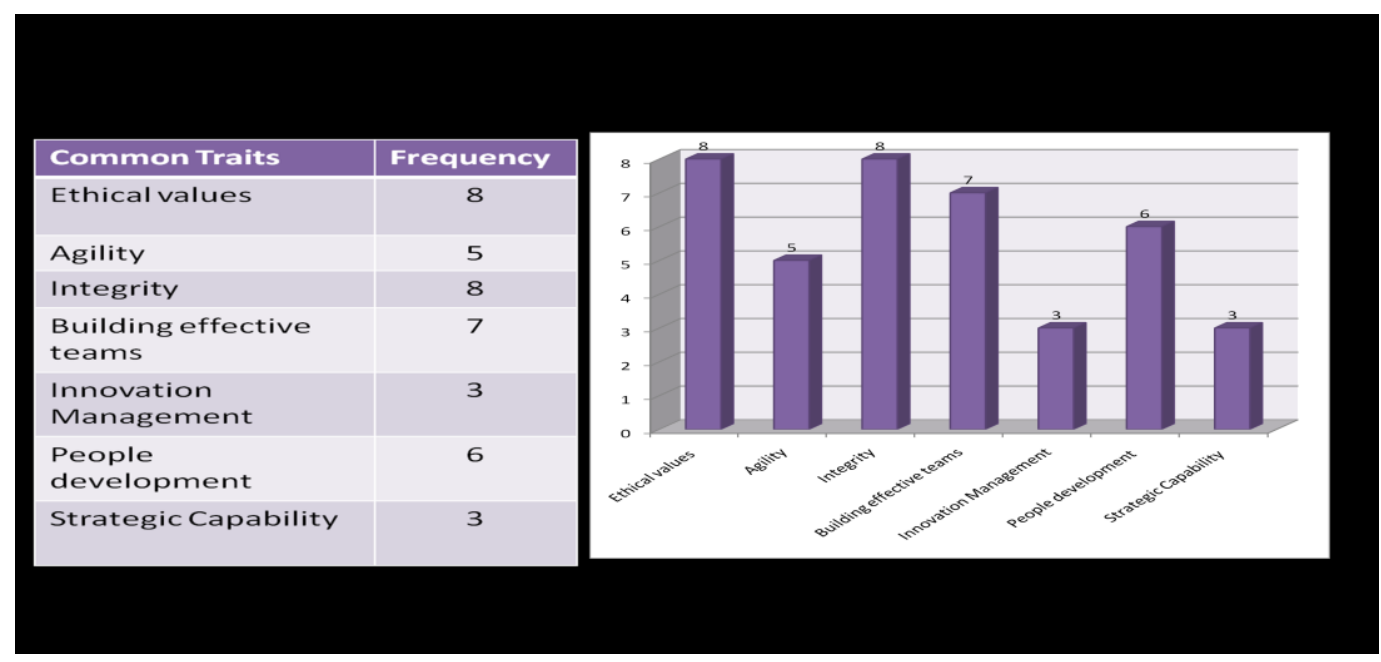

Analysis: Respondents named 'Ethical Values', 'Integrity' and 'Ability to Build Effective Teams' as the three main leadership attributes in turbulent times 


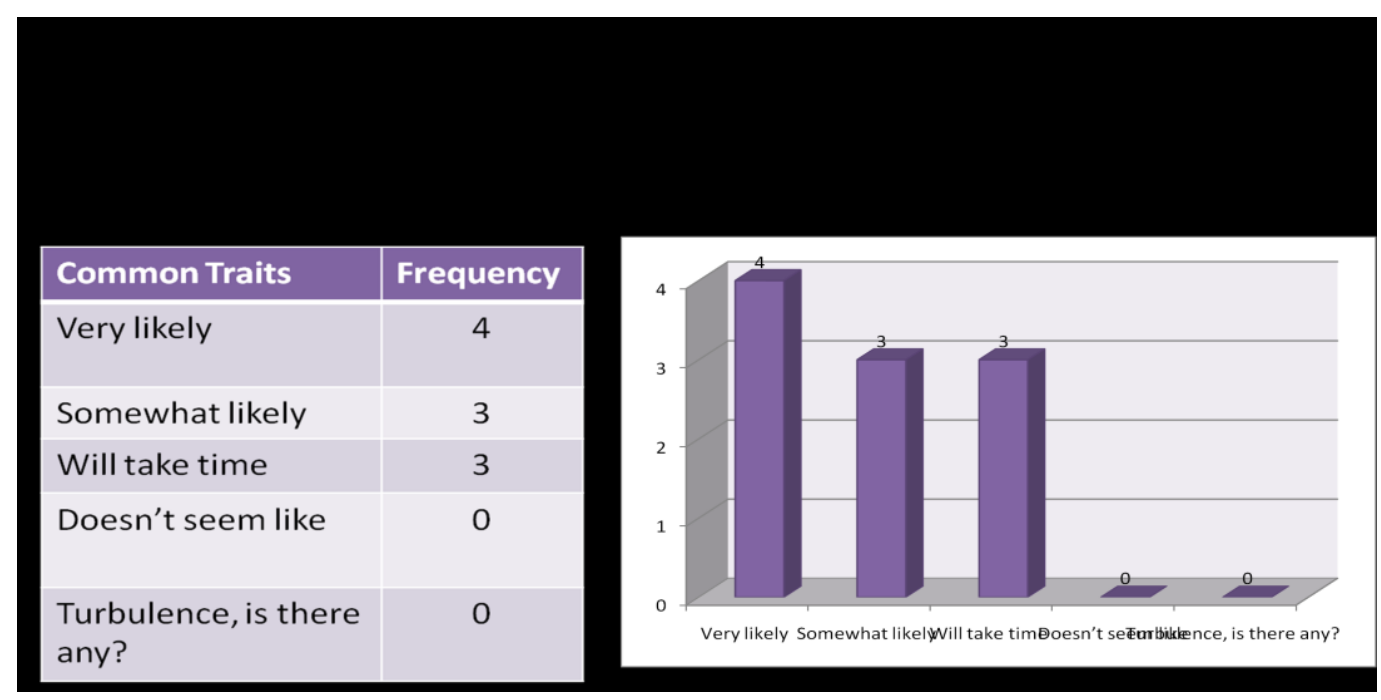

Analysis: It was heartening to notice that senior leaders in Tata Power expressed great confidence in the ability of the organization to successfully navigate the current difficult environment. However, we also sensed a pragmatism and cautiousness which was an acknowledgement of the fact that the external environment is definitely challenging.

\section{Reference Sources for Secondary Research:}

\section{ANNEXURE II}

1. The 2020 Workplace - Jeanne C Meister \& Karie Willyerd

2. Best Practices for Developing Change Leadership in Turbulent Times - The Conference Board Councils on Leadership Development, Organizational Learning, HR and Talent Management, and Diversity and Inclusion

3. Capitalizing on Complexity, IBM Corporation 2010

http://www-935.ibm.com/services/us/ceo/ceostudy 2010/index.html

4. https://en.wikipedia.org/wiki/Leadership\#Organizations

5. McKinsey Global survey on Leadership through the Crisis and after

6. Harvard Business Review - Leadership in a (Permanent) Crisis - Ronald Heifetz, Alexander Grashow, and Marty Linsky

7. McKinsey Quarterly - July 2009 - Leadership lessons for hard times - Dennis Carey, Michael PatsalosFox, and Michael Useem

8. ILO Report on Global Employment Trends, 2013

9. http://blogs.wsj.com/indiarealtime/2013/02/28/the-perils-of-unfulfilled-indian-youth/

10. State of Indian Economy, 2013 - Deloitte Paper 